\title{
PENGARUH STRATEGI REACT (RELATING, EXPERIENCING, APPLYING, COOPERATING, TRANSFERING) TERHADAP KEMAMPUAN PEMAHAMAN KONSEP MATEMATIS PESERTA DIDIK KELAS VII SMP NEGERI 1 BANGKINANG
}

\author{
Ulfa Santi Novri ${ }^{1}$, Zulfah $^{2}$, Astuti $^{3}$ \\ ${ }^{1,2,3}$ Universitas Pahlawan Tuanku Tambusai, Jl. Tuanku Tambusai No 23 Bangkinang \\ Email penulis pertama: ulfasantinovri@gmail.com
}

\begin{abstract}
This researched aim to know whether there is any effect of REACT (Relating, Experiencing, Applying, Cooperating, Transfering) strategy toward mathematical concepts understanding of seventh years students at state junior high school 1 Bangkinang. The formulation of problem is "Is there significant effect between mathematical concepts understanding of students whole REACT (Relating, Experiencing, Applying, Cooperating, Transfering) strategy and students who obtain conventional learning of seventh years students at state junior high school 1 Bangkinang?". This research was Quasi Experimental research namely research erdirectroleas teachers in the learning process and teacher as observer. Subjects in this study were students of of seventh years students at state junior high school 1 Bangkinang, while the object of this researchis mathematical concepts understanding. Collecting data in this research using documentation and test. Documentation used to know history of school, teacher and students situation, pre-existing facilities in schools. While the testis used to know the level of mathematical concepts understanding of students.Based on an analysis of data obtained by average of for experiment class 80,046 while the control class 58,240 and $t$ value for 4,314 while the value of $t$ table at significant level of $5 \%=2.00$ then $t$ coun $t \geq t$ table or $4,314 \geq 2.00$. This means that $\mathrm{Ha}$ is accepted and Ho is rejected. It can be concluded that there is effect of REACT (Relating, Experiencing, Applying, Cooperating, Transfering) Strategy toward Mathematical Concepts Understanding of Seventh Years Students at State Junior High School 1 Bangkinang.
\end{abstract}

Keywords : REACT (Relating, Experiencing, Applying, Cooperating, Transfering Strategy), Mathematical Concepts Understanding.

\begin{abstract}
Abstrak
Penelitian ini bertujuan untuk mengetahui ada tidaknya pengaruh strategi pembelajaran REACT (Relating, Experiencing, Applying, Cooperating, Transfering) terhadap kemampuan pemahaman konsep matematis peserta didik kelas VII SMP Negeri 1 Bangkinang. Adapun rumusan masalahnya adalah "Apakah terdapat pengaruh signifikan pemahaman konsep matematis antara peserta didik yang belajar menggunakan strategi REACT (Relating, Experiencing, Applying, Cooperating, Transfering) dan peserta didik yang memperoleh pembelajaran konvensional kelas VII di SMP Negeri 1 Bangkinang?". Penelitian ini merupakan penelitian quasi eksperimen yaitu peneliti berperan langsung sebagai guru dalam proses pembelajaran. Subjek dalam penelitian ini adalah peserta didik kelas VII SMP Negeri 1 Bangkinang dan yang menjadi objek penelitian ini adalah pemahaman konsep matematis. Pengambilan data dalam penelitian ini mengunakan dokumentasi dan tes. Dokumentasi digunakan untuk mengetahui sejarah sekolah, keadaan guru dan peserta didik, sarana dan prasarana yang ada di sekolah. Sedangkan test dipergunakan untuk mengetahui tingkat pemahaman konsep matematika peserta didik. Berdasarkan hasil analisis data diperoleh rata-rata untuk kelas eksperimen 80,046 sedangkan kelas kontrol 58,240 dan nilai $t_{\text {hitung }}$ sebesar 4,314 sedangkan nilai $t_{\text {tabel }}$ pada taraf signifikan $5 \%=2,00$ maka $t_{\text {hitung }} \geq \mathrm{t}_{\text {tabel }}$ atau $4,314 \geq 2,00$. Ini berati bahwa $h_{a}$ diterima dan $h_{o}$ ditolak. Maka dapat diambil kesimpulan bahwa terdapat pengaruh strategi REACT (Relating, Experiencing, Applying, Cooperating, Transfering) terhadap kemampuan pemahaman konsep matematis peserta didik kelas VII SMP Negeri 1 Bangkinang.
\end{abstract}

Kata Kunci : Strategi REACT (Relating, Experiencing, Applying, Cooperating, Transfering), Pemahaman Konsep Matematis. 
Matematika adalah salah satu mata pelajaran yang sangat penting dalam dunia pendidikan, karena pelajaran matematika dapat membuat peserta didik berfikir logis, rasional, kritis dan luas, pernyataan ini sejalan dengan tujuan pendidikan nasional, yaitu: Mempersiapkan anak didik agar mampu menghadapi perubahan dalam dunia yang senantiasa berubah ini, bertindak atas dasar pemikiran logis, rasional, kritis, dan agar anak didik mampu menggunakan matematika dalam kehidupan sehari-hari dan dalam mempelajari berbagai ilmu pengetahuan (Astuti, 2017).

Adapun salah satu tujuan pembelajaran matematika yang tercantum dalam Peraturan Menteri Pendidikan Nasional RI Nomor 58 Tahun 2014, yaitu: memahami konsep matematis, merupakan kompetensi dalam menjelaskan keterkaitan antarkonsep dan menggunakan konsep maupun algoritma, secara luwes, akurat, efisien, dan tepat, dalam pemecahan masalah. Sehingga terlihat jelas bahwa matematika bertujuan agar peserta didik memiliki kemampuan pemahaman konsep matematis.

Berkaitan dengan pentingnya pemahaman konsep matematis, peneliti melakukan observasi, wawancara, serta melihat dokumentasi latihan dan hasil ulangan peserta didik pada materi sebelumnya. Berdasarkan hasil wawancara dengan guru bidang studi matematika di SMP Negeri 1 Bangkinang diperoleh realita bahwa pemahaman konsep matematis peserta didik kelas VII belum begitu baik yang dapat dilihat dari gejala-gejalanya.

Peserta didik mengerti pada saat guru menjelaskan, tetapi peserta didik sulit untuk mengungkapkan kembali dari apa yang telah dipelajari. Peserta didik kurang mampu mengaplikasikan konsep dasar matematika jika diputar kedalam bentuk yang lain. Peserta didik hanya tertuju pada materi yang sedang dipelajari saja dan pada pertemuan selanjutnya peserta didik lupa tentang materi yang telah dipelajari padahal materi itu ada hubungannya. Beberapa peserta didik belum dapat mengaplikasikan konsep pelajaran ke dalam kehidupan mereka.

Berdasarkan gejala-gejala yang telah dikemukakan, persoalannya adalah bagaimana memfasilitasi peserta didik untuk memiliki kemampuan pemahaman konsep matematis. Untuk itu suatu inovasi dalam pembelajaran sangat diperlukan, hal ini menitikberatkan pada aktivitas belajar peserta didik, membantu peserta didik jika ada kesulitan atau membimbingnya untuk memperoleh suatu kesimpulan. Cara yang dapat dilakukan adalah dengan melaksanakan perbaikan pada proses pembelajaran (Zulfah, 2017).

Salah satu upaya perbaikan pada proses pembelajaran yang dapat dilakukan untuk mengatasi permasalahan di atas yaitu dengan mengadakan variasi proses pembelajaran, misalnya dengan penerapan strategi pembelajaran yang dapat melibatkan peserta didik secara langsung untuk membangun pemahamannya. Strategi yang diyakini dapat membantu guru dalam meningkatkan kemampuan pemahaman konsep matematis peserta didik.

Strategi pembelajaran yang diharapkan dapat mengaktifkan, memahamkan, dan mengembangkan daya pikir peserta didik adalah strategi yang dapat mengaitkan materi dengan kehidupan nyata dan pengetahuan awal peserta didik, melibatkan peserta didik dalam pemecahan 
Pengaruh Strategi REACT (Relating, Experiencing, Applying, Cooperating, Transfering) Terhadap Kemampuan

masalah dan manipulasi alat peraga, melibatkan peserta didik untuk belajar secara kooperatif, memberikan kesempatan kepada peserta didik untuk menemukan sendiri, mengaplikasikan, dan mentransfer konsep yang dipelajari. Salah satu strategi pembelajaran yang dapat digunakan adalah REACT (Relating, Experiencing, Applying, Cooperating, Transfering) (Rizka, 2014).

Penerapan strategi REACT dalam pembelajaran matematika dapat melatih peserta didik untuk mengembangkan kemampuan pemahaman konsep matematisnya. Hal ini disebabkan karena pada pembelajaran dengan strategi REACT peserta didik dituntut untuk memahami konsep berdasarkan permasalahan yang diberikan guru dengan mengaitkannya dengan pengalaman dan pengetahuan awal yang dimiliki peserta didik. Pembelajaran tidak hanya berupa pemberian konsep dari guru, tetapi peserta didiklah yang aktif mengkonstruksi pengetahuannya dengan bimbingan guru.

Berdasarkan uraian tersebut, maka penulis tertarik untuk melakukan penelitian dengan judul "Pengaruh Strategi REACT (Relating, Experiencing, Applying, Cooperating, Transfering) terhadap Kemampuan Pemahaman Konsep Matematis Peserta Didik Kelas VII SMP Negeri 1 Bangkinang”. Strategi REACT merupakan strategi pembelajaran dengan pendekatan kontekstual yang ditawarkan oleh Center of Occupational Research and Development (CORD) (Lefrida, 2014). Strategi REACT Pertama kali dikembangkan oleh Micheal L, Crawford di Amerika Serikat (Siahaan, 2012). Perencanaan pembelajaran pada strategi REACT disusun untuk lima pokok dasar pembelajaran, yaitu: a. Relating (mengaitkan)

Relating (mengaitkan) merupakan belajar dalam konteks pengalaman kehidupan nyata atau pengetahuan yang sebelumnya (Rizka, 2014). Guru menggunakan strategi ini ketika ia mengaitkan konsep baru dengan sesuatu yang sudah dikenal peserta didik (Helmiati, 2012: 51). Guru mengawali pembelajaran dengan mengajukan pertanyaan-pertanyaan yang dapat dijawab oleh hampir semua peserta didik melalui pengalaman hidupnya diluar kelas.

b. Experiencing (mengalami)

Experiencing (mengalami) merupakan belajar berupa kegiatan peserta didik untuk berproses secara aktif dengan hal yang dipelajari dan berupaya melakukan eksplorasi terhadap hal yang dikaji, berusaha menemukan, dan menciptakan hal baru dari yang sudah dipelajarinya. peserta didik dibimbing untuk melakukan percobaan sehingga peserta didik mengalami sendiri konsep yang dipelajari (Laelatunnajah, 2018).

c. Applying (menerapkan)

Applying (menerapkan) adalah belajar dengan menempatkan konsep-konsep untuk digunakan, dengan memberikan latihan-latihan yang realistik dan relevan (Rizka, 2014). Guru mengajak peserta didik untuk berfikir dengan menerapkan konsep untuk melakukan aktivitas pemahaman konsep. Pada Applying, peserta didik bisa mengetahui dan memahami aplikasi dari konsep matematika tersebut dalam pemecahan masalah di dunia nyata (Husna, 2014). 
d. Cooperating (bekerjasama)

Cooperating (bekerjasama) adalah belajar dengan konteks saling berbagi, merespon, dan berkomunikasi dengan pelajar lainnya (Husna, 2014). Pembelajaran dengan mengkondisikan peserta didik agar bekerja sama, merespon dan berkomunikasi antar peserta didik (Laelatunnajah, 2018).

e. Transfering (mentransfer)

Transferring (mentransfer) adalah belajar dengan menggunakan pengetahuan dalam konteks baru (Rizka, 2014). Transferring pengetahuan dilakukan peserta didik berdasarkan pengetahuan yang dimilikinya. Guru dapat memberikan permasalahan yang memiliki konteks dan kombinasi konsep yang lebih kompleks, atau yang memiliki kaitan dengan disiplin ilmu lain.

Pemahaman konsep terdiri atas dua kata, yaitu pemahaman dan konsep. Pemahaman merupakan terjemahan dari istilah understanding yang diartikan sebagai penyerapan arti suatu materi yang dipelajari (Murizal, 2012). Konsep merupakan asas pada pengajaran dan pembelajaran (Zakaria, 2007: 148). Konsep merupakan sesuatu yang tergambar dalam pikiran, suatu pemikiran, gagasan, atau suatu pengertian (Mawaddah, 2016).

Pemahaman konsep matematis diterjemahkan dari istilah mathematical concept understanding merupakan kemampuan matematis yang sangat penting dan harus dimiliki peserta didik dalam belajar matematika. Pemahaman terhadap konsep merupakan kemampuan dasar untuk mencapai kemampuan matematis yang lebih tinggi seperti penalaran, koneksi, komunikasi, representasi, dan pemecahan masalah (Husna, 2014).

Berdasarkan uraian diatas dapat disimpulkan bahwa pemahaman konsep matematis merupakan satu kompetensi dasar dalam belajar matematika yang meliputi kemampuan menyerap suatu materi, mengingat rumus dan konsep matematika serta menerapkannya dalam kasus sederhana, memperkirakan kebenaran suatu pernyataan, dan menerapkan rumus dan teorema dalam penyelesaian masalah.

Indikator yang menunjukkan pemahaman konsep menurut Peraturan Menteri Pendidikan Nasional RI Nomor 58 Tahun 2014 yang termuat dalam kurikulum 2013 adalah:

a. Menyatakan ulang konsep yang telah dipelajari.

b. Mengklasifikasikan objek-objek berdasarkan dipenuhi tidaknya persyaratan yang membentuk konsep tersebut.

c. Mengidentifikasi sifat-sifat operasi atau konsep.

d. Menerapkan konsep secara logis.

e. Memberikan contoh atau contoh kontra (bukan contoh) dari konsep yang dipelajari.

f. Menyajikan konsep dalam berbagai macam bentuk representasi matematis (tabel, grafik, diagram, gambar, sketsa, model matematika, atau cara lainnya)

g. Mengaitkan berbagai konsep dalam matematika maupun di luar matematika.

h. Mengembangkan syarat perlu dan/atau syarat cukup suatu konsep. 
Pengaruh Strategi REACT (Relating, Experiencing, Applying, Cooperating, Transfering) Terhadap Kemampuan

\section{METODE}

Subjek dalam penelitian ini adalah peserta didik kelas VII SMP Negeri 1 Bangkinang dengan kelas VII B sebagai kelas eksperimen dan kelas VII A sebagai kelas kontrol. Sedangkan yang menjadi objek penelitian ini adalah pemahaman konsep matematis.

Jenis penelitian ini adalah Quasi Eksperimen dan desain yang digunakan adalah Desain Kelompok Kontrol Prates-Pasca Tes Acak (Randomized Pre Test-Post Test Control Group Desain). Rancangan penelitian ini dapat dilihat pada Tabel1:

\section{Tabel 1}

Rancangan Penelitian

\begin{tabular}{|c|c|c|c|c|}
\hline & Kelompok & Pre Test & Perlakuan & Post Test \\
\hline Acak & A (Kel. Eksperimen) & $\mathbf{O}_{1}$ & $\mathbf{X}$ & $\mathbf{O}_{2}$ \\
\hline Acak & B (Kel. Kontrol) & $\mathbf{O}_{3}$ & - & $\mathbf{O}_{4}$ \\
\hline
\end{tabular}

Sumber: Syaodih (2011: 204)

Keterangan :

X : Pembelajaran dengan strategi REACT (Relating, Experiencing, Applying, Cooperating, Transfering)

- : Pembelajaran konvensional atau biasa

$\mathrm{O}_{1}$ : Pre test kelas eksperimen

$\mathrm{O}_{2}$ : Post test kelas eksperimen

$\mathrm{O}_{3}$ : Pre test kelas kontrol

$\mathrm{O}_{4}$ : Post test kelas control

Pengambilan data dalam penelitian ini mengunakan observasi, dokumentasi dan tes. Observasi digunakan saat pertama kali melihat lingkungan sekolah dan untuk mengobservasi peneliti melakukan pembelajaran menggunakan strategi REACT. Dokumentasi digunakan untuk mengetahui sejarah sekolah, keadaan guru dan peserta didik, sarana dan prasarana yang ada di sekolah. Sedangkan tes dipergunakan untuk mengetahui tingkat pemahaman konsep matematika peserta didik.

Analisis data dalam penelitian ini ada 2 yaitu:

1. Analisis Tahap Awal

Sebelum sampel diberi perlakuan, maka perlu dianalisis dahulu melalui uji normalitas dan uji homogenitas. Hal ini dilakukan untuk mengetahui apakah kedua kelompok sampel berasal dari kondisi awal yang sama. Data yang digunakan dalam analisis tahap awal berasal dari nilai tes awal (pre test).

a. Uji Normalitas

Uji normalitas merupakan salah satu uji prasyarat untuk memenuhi asumsi kenormalan dalam analisis data statistik parametrik.Uji normalitas dilakukan untuk mengetahui apakah data berdistribusi normal atau tidak. Data diuji normalitasnya dengan uji Liliefors (Lo). Dengan kriteria pengujian : 
Jika $L_{\text {hitung }}<L_{\text {tabel }}$ terima $\mathrm{H}_{0}$, dan

Jika $L_{\text {hitung }} \geq L_{\text {tabel }}$ tolak $\mathrm{H}_{0}$

b. Uji Homogenitas

Uji homogenitas merupakan sebuah uji yang harus dilakukan untuk melihat kelas yang diteliti homogen atau tidak. (Eka Lestari, 2017: 248) Pada penelitian tahap awal kelas yang akan diteliti sudah diuji homogenitasnya, dengan cara menggunakan uji Bartlett.

Jika : $\chi_{\text {hitung }}^{2}>\chi_{\text {tabel }}^{2}$, tidak homogen

Jika $: \chi_{\text {hitung }}^{2} \leq \chi_{\text {tabel }}^{2}$, homogen

2. Analisis Tahap Akhir

a. Uji Hipotesis

Analisis tahap akhir merupakan analisis untuk menguji hipotesis penelitian menggunakan uji hipotesis setelah kedua sampel diberi perlakuan yang berbeda. Sebelum uji hipotesis terlebih dahulu dilakukan pengujian prasyarat analisis yaitu:

1) Uji Normalitas

Uji normalitas digunakan untuk mengetahui apakah kedua kelompok sampel dengan pembelajaran menggunakan strategi pembelajaran REACT dan pembelajaran konvensional berdistribusi normal atau tidak. Adapun langkah-langkah dan rumus yang digunakan sama dengan uji normalitas pada analisis data tahap awal.

2) Uji Homogenitas

Penelitian tahap akhir kelas yang akan diteliti sudah diuji homogenitasnya, dengan cara menggunakan uji $\mathrm{F}$ dengan rumus:

$$
F=\frac{\text { Varians Terbesar }}{\text { Varians Terkecil }}
$$

Lalu hasilnya dibandingkan dengan $F$ tabel. Jika diperoleh $F_{h} \leq F_{t}$, maka sampel dikatakan mempunyai varians yang sama atau homogen.

3) Uji Hipotesis

Jika data berdistribusi normal dan homogen maka pengujian dengan uji-t. Jika data berdistribusi normal tetapi tidak homogen maka pengujian dengan uji-t'. Jika data tidak berdistribusi normal maka pengujian dengan uji statistik non-parametrik. Karena data dalam penelitian ini berdistribusi normal dan homogen maka pengujian hipotesis menggunakan uji t, yaitu:

$$
t_{\text {hitung }}=\frac{M_{x}-M_{y}}{\sqrt{\left(\frac{S D_{x}}{\sqrt{N-1}}\right)^{2}+\left(\frac{S D_{y}}{\sqrt{N-1}}\right)^{2}}}
$$


Pengaruh Strategi REACT (Relating, Experiencing, Applying, Cooperating, Transfering) Terhadap Kemampuan

\section{HASIL DAN PEMBAHASAN}

Pelaksanaan strategi REACT dan pembelajaran konvensional dilakukan dengan 6 kali pertemuan yaitu 1 kali pre test, 4 kali pertemuan menyajikan data dan 1 kali post test. Selama dilakukannya proses penelitian, setiap aktivitas peneliti dalam proses pembelajaran dinilai oleh guru mata pelajaran matematika yaitu Ibu Ruslina, S.Pd. Semua aktivitas peneliti tertera dalam Lembar Observasi Guru dan diperoleh rata-rata aktivitas guru yaitu 91,11\%. Setiap aktivitas peserta dalam proses pembelajaran berlangsung dinilai oleh peneliti sendiri dibantu oleh rekan peneliti yaitu Erni Anika. Semua aktivitas peserta didik tertera dalam Lembar Observasi Peserta Didik dan diperoleh rata-rata aktivitas peserta didik sebesar 87,22\%.

Data yang disajikan dalam penelitian ini adalah data yang berkaitan dengan variabel yang diteliti yaitu data nilai hasil post test kemampuan pemahaman konsep matematis. Soal post test terdiri dari 8 soal yang dibuat sesuai indikator yang menunjukkan pemahaman konsep menurut Peraturan Menteri Pendidikan Nasional RI Nomor 58 Tahun 2014 yang termuat dalam kurikulum 2013. Pemahaman konsep peserta didik yang belajar dengan strategi pembelajaran REACT (Relating, Experiencing, Applying, Cooperating, Transfering) di kelas eksperimen lebih baik daripada peserta didik yang belajar dengan pembelajaran konvensional di kelas kontrol. Hal itu terlihat pada perbedaan jumlah peserta didik kelas kontrol dan peserta didik kelas eksperimen yang benar menjawab soal post test berdasarkan indikator-indikatornya.

Pengujian persyaratan analisis sebelum menggunakan uji hipotesis yaitu dengan uji normalitas dan uji homogenitas. Uji normalitas nilai post test kemampuan pemahaman konsep matematis peserta didik kelas eksperimen dan peserta didik kelas kontrol dilakukan dengan menggunakan uji Lilifors. Hasil perhitungannya dapat dilihat pada tabel 2

\section{Tabel 2}

Uji Normalitas Data Post Test Kemampuan Pemahaman Konsep Matematis Peserta didik Kelas Eksperimen dan Peserta didik Kelas Kontrol

\begin{tabular}{|c|c|c|}
\hline \multirow{2}{*}{ Nilai } & \multicolumn{2}{|c|}{ Kelas } \\
\cline { 2 - 3 } & Eksperimen & Kontrol \\
\hline$L_{\text {hitung }}$ & 0,1062 & 0,0921 \\
\hline$L_{\text {tabel }}$ & 0,161 & 0,161 \\
\hline Keterangan & Normal & Normal \\
\hline
\end{tabular}

Berdasarkan hasil uji normalitas pada tabel 2 diperoleh $L_{\text {hitung }}<L_{\text {tabel }}$, sehingga dapat disimpulkan bahwa kemampuan pemahaman konsep matematis peserta didik pada kelas eksperimen maupun kelas kontrol berdistribusi normal. Analisis data juga dilaksanakan menggunakan SPSS (Statistical Product and Service Solution), yang bertujuan untuk memperkuat analisis secara manual. Analisis data dengan menggunakan SPSS digunakan uji Kolmogorov-Smirnov. Hasil uji KolmogorovSmirnov distribusi nilai post test peserta didik kelas eksperimen adalah normal. Hal ini bisa dilihat pada tingkat signifikan alat uji, yaitu 0,164 > 0,05. Begitu juga dengan hasil uji Kolmogorov-Smirnov 
distribusi nilai post test peserta didik kelas kontrol adalah normal. Hal ini bisa dilihat pada tingkat signifikan alat uji, yaitu $0,200>0,05$. Maka dari output SPSS dapat disimpulkan bahwa kelas eksperimen dan kelas kontrol memiliki data yang berdistribusi normal.

Uji homogenitas dilakukan untuk mengetahui apakah kelas eksperimen dan kelas kontrol homogen. Dilakukan dengan uji $\mathrm{F}$ yaitu membandingkan $\mathrm{F}_{\text {hitung }}$ dan $\mathrm{F}_{\text {tabel }}$ dimana nilai $\mathrm{F}_{\text {hitung }}$ diperoleh dengan cara membandingkan nilai varians terbesar dengan nilai varians terkecil. Hasil perhitungan uji homogenitas pada data kemampuan pemahaman konsep matematis peserta didik kelas eksperimen dapat dilihat pada tabel 3

\section{Tabel 3}

Uji Homogenitas Post Test Kemampuan Pemahaman Konsep Matematis Peserta didik Kelas Eksperimen dan Kelas Kontrol

\begin{tabular}{|c|c|c|c|c|}
\hline \multirow{2}{*}{$\begin{array}{c}\text { Pemahaman } \\
\text { Konsep }\end{array}$} & Kelas & Variansi $\left(S^{2}\right)$ & $F_{\text {hitung }}$ & $F_{\text {tabel }}$ \\
\cline { 2 - 3 } & Eksperimen & 279,5049858 & \multirow{2}{*}{1,376170606} & 1,90 \\
\cline { 2 - 3 } & Kontrol & 384,6465456 & & \\
\hline
\end{tabular}

Berdasarkan tabel 3 dapat dilihat kemampuan pemahaman konsep matematis peserta didik kelas eksperimen dan kelas kontrol mempunyai variansi yang homogen karena $F_{\text {hitung }} \leq F_{\text {tabel }}$. Uji homogenitas juga dibantu dengan menggunakan SPSS (Statistical Product and Service Solution). Uji homogenitas dengan SPSS menggunakan uji Levene's. Dari pengujian dengan menggunakan SPSS diperoleh nilai P-value $(0,478)>\alpha(0,05)$ maka dapat disimpulkan bahwa data adalah homogen.

Berdasarkan uji persyaratan analisis diperoleh bahwa kelompok data kemampuan pemahaman konsep matematis peserta didik kelas eksperimen dan kelas kontrol berdistribusi normal dan homogen. Kedua syarat untuk uji hipotesis telah dipenuhi, maka analisis data yang digunakan untuk menguji hipotesis dalam penelitian ini adalah dengan menggunakan uji-t. Hasil perhitungan uji hipotesis dapat dilihat pada tabel 4

\section{Tabel 4}

Uji Hipotesis Post Test Kemampuan Pemahaman Konsep Matematis Peserta didik Kelas Eksperimen dan Kelas Kontrol

\begin{tabular}{|c|c|c|}
\hline \multirow{2}{*}{ Statistik } & \multicolumn{2}{|c|}{ Kemampuan Pemahaman Konsep } \\
\cline { 2 - 3 } & Eksperimen & Kontrol \\
\hline $\mathrm{N}$ & 27 & 27 \\
\hline $\bar{x}$ & 80,0462963 & 58,24074074 \\
\hline$S^{2}$ & 16,71840261 & 19,61240795 \\
\hline$t_{\text {hitung }}$ & \multicolumn{2}{|c|}{4,314} \\
\hline$t_{\text {tabel }}$ & \multicolumn{2}{|c|}{2,00} \\
\hline
\end{tabular}

Analisis uji hipotesis dengan taraf nyata $(\alpha)=5 \%$ diperoleh nilai $t_{\text {tabel }}=2,00$. Jika dibandingkan dengan $t_{\text {hitung }}=4,314$, diperoleh $t_{\text {hitung }}>t_{\text {tabel }}$ maka dapat disimpulkan $\mathrm{H}_{\mathrm{a}}$ diterima. Analisis data juga dilaksanakan menggunakan SPSS bertujuan untuk memperkuat analisis secara manual. Hasil output pengujian hipotesis dengan menggunakan SPSS menunjukkan bahwa pada Sig (2.tailed) terlihat nilai probabilitas 0.000 , karena nilai probabilitas $0.000<0.05$ maka dapat disimpulkan tolak $\mathrm{H}_{0}$ dan $\mathrm{H}_{\mathrm{a}}$ diterima. 
Pengaruh Strategi REACT (Relating, Experiencing, Applying, Cooperating, Transfering) Terhadap Kemampuan

Artinya hasil analisis ini menunjukkan bahwa terdapat pengaruh yang signifikan antara kemampuan pemahaman konsep matematis peserta didik yang belajar menggunakan strategi pembelajaran REACT (Relating, Experiencing, Applying, Cooperating, Transfering) dan peserta didik yang belajar menggunakan pembelajaran konvensional di kelas VII SMP Negeri 1 Bangkinang.

\section{KESIMPULAN}

Penelitian ini bertujuan untuk melihat pengaruh setelah menggunakan strategi pembelajaran REACT (Relating, Experiencing, Applying, Cooperating, Transfering) terhadap kemampuan pemahaman konsep matematis peserta didik. Hasil dari perhitungan uji t dengan taraf nyata $(\alpha)=5 \%$ diperoleh nilai $t_{\text {tabel }}=2,00$. Jika dibandingkan dengan $t_{\text {hitung }}=4,314$, diperoleh $t_{\text {hitung }}>t_{\text {tabel }}$ maka dapat disimpulkan $\mathrm{H}_{\mathrm{o}}$ ditolak dan $\mathrm{H}_{\mathrm{a}}$ diterima. Analisis data juga dilaksanakan menggunakan SPSS bertujuan untuk memperkuat analisis secara manual. Hasil output pengujian hipotesis dengan menggunakan SPSS menunjukkan bahwa pada Sig (2.tailed) terlihat nilai probabilitas 0.000 , karena nilai probabilitas $0.000<0.05$ maka dapat disimpulkan $\mathrm{H}_{\mathrm{o}}$ ditolak dan $\mathrm{H}_{\mathrm{a}}$ diterima.

Maka dapat disimpulkan bahwa terdapat pengaruh yang signifikan antara kemampuan pemahaman konsep matematis peserta didik yang belajar menggunakan strategi REACT (Relating, Experiencing, Applying, Cooperating, Transfering) dan peserta didik yang belajar menggunakan pembelajaran konvensional di SMP Negeri 1 Bangkinang.

Berikut ini ada beberapa saran yang ditujukan pada guru, calon guru, peserta didik dan peneliti lain diantaranya:

1. Kepada guru dan calon guru matematika, strategi REACT (Relating, Experiencing, Applying, Cooperating, Transfering) merupakan alternatif pembelajaran yang dapat digunakan pada kegiatan pembelajaran terutama bagi guru yang selama ini menggunakan model pembelajaran konvensional. Namun, hendaknya terlebih dahulu memahami langkah-langkah dari strategi REACT (Relating, Experiencing, Applying, Cooperating, Transfering).

2. Kepada peneliti lain, dapat melakukan penelitian dengan peninjauan lain misalnya kemampuan awal, minat belajar, maupun ntuk meneliti kemampuan matematis lainnya seperti pemecahan masalah, penalaran, komunikasi dan koneksi matematis peserta didik.

3. Kepada peserta didik hendaknya meningkatkan semangat dan intensitas belajar matematika baik di sekolah maupun di luar sekolah, sehingga dapat meningkatkan kemampuan matematis serta prestasi belajar matematika.

\section{DAFTAR PUSTAKA}

Astuti, Nurhidayah s. (2017). Pengembangan Lembar Kerja Siswa (LKS) Pada Mata Pelajaran Matematika Siswa Kelas X SMA. jurnal cendekia: jurnal pendidikan matematika, 1(2), hlm.13-24.

Effandi Zakaria dkk, 2007, Trend Pengajaran dan Pembelajaran Matematik, Kuala Lumpur: Prin-AD Sdn. Bhd 
Helmiati. (2012). Model Pembelajaran. Pekanbaru: Aswaja Pressindo.

Husna, F. E., Dwina, F., \& Murni, D. (2014). Penerapan Strategi REACT Dalam Meningkatkan Kemampuan Pemahaman Konsep Matematika Siswa Kelas X SMAN 1 Batang Anai. Jurnal pendidikan matematika, 3(1), hlm.26-30.

Karunia eka lestari, dkk. (2017). Penelitian Pendidikan Matematika. Karawang: Aditama.

Mawaddah, S. (2016). Kemampuan Pemahaman Konsep Matematis Siswa SMP dalam Pembelajaran Menggunakan Model Penemuan Terbimbing (Discovery Learning). EDU-MAT Jurnal Pendidikan Matematika, 4(1), 76-85.

Murizal, A. (2012). Pemahaman Konsep Matematis dan Model Pembelajaran Quantum Teaching. Jurnal Pendidikan Matematika, 1(1), hlm.19-23.

Peraturan Menteri Pendidikan Nasional RI Nomor 58 Tahun 2014. (n.d.).

Purwosusilo. (2014). Peningkatan Kemampuan Pemahaman Dan Pemecahan Masalah Matematik Siswa SMK Melalui Strategi Pembelajaran REACT (Studi Eksperimen Di SMK Negeri 52 Jakarta). Jurnal Pendidikan Dan Keguruan, 1(2), hlm.21-29.

Rizka, N. (2014). Pengaruh Penerapan Strategi Relating, Experiencing, Applying, Cooperating, Transferring Terhadap Kemampuan Pemahaman Konsep Matematika Siswa Kelas X SMAN 2 Payakumbuh. Jurnal Pendidikan Matematika, 3(2), hlm. 44-48.

Siahaan, F. B. (2012). Upaya Meningkatkan Pemahaman Konsep Matematika dengan Model Pembelajaran Inkuiri Terbimbing Siswa Kelas VIII C SMP Negeri 11 Yogyakarta, 2(2) hlm.56-64.

Sukmadinata, N. S. (2011). Metode Penelitian Pendidikan. Bandung: PT. Remaja Rosdakarya.

Zulfah. (2017). Tahap Preliminary Research Pengembangan LKPD Berbasis Pbl Untuk Materi Matematika Semester 1 Kelas VIII SMP. Journal Cendekia: Jurnal Pendidikan Matematika, 1(2), hlm 1-12. 